\title{
A Study on the Efficiency in the Children Suffering from Attention Deficit Hyperactivity Disorder
}

\author{
Mehri Farokhzadeh $^{1}$, Masoumeh Mohammadi Khashouei ${ }^{1} \&$ Shaghayegh Jaberzadeh Ansari ${ }^{2}$ \\ ${ }^{1}$ Department of Psychology, Najafabad Branch, Islamic Azad University, Najafabad, Isfahan, Iran \\ ${ }^{2}$ Department of Psychology, Alzahra University, Tehran, Iran \\ Correspondence: Masoumeh Mohammadi Khashouei, Department of Psychology, Najafabad Branch, Islamic \\ Azad University, Najafabad, Isfahan, Iran. E-mail: mmohammadi1392@gmail.com
}

Received: August 12, 2016

Accepted: August 22, 2016

Online Published: October 18, 2016

doi:10.5539/res.v8n4p72

URL: http://dx.doi.org/10.5539/res.v8n4p72

\begin{abstract}
The present study aims at investigating the efficiency of the children suffering from hyperactivity disorder in the continuous function test of auditory and visual stimuli (IVA) in order to improve and promote the mental health of these kinds of people. This is of descriptive-comparative type of study. The 30 participants of the present study are the students of Tehran schools which have been chosen through cluster sampling among two groups of hyperactive and normal boys and girls who aged from 12 to 18 . The Connors questionnaires and IVA+AE test were used to achieve the goal. The data were analyzed using SPSS-20 and multivariable statistical analyses method. The findings showed that there is a significant correlation among the focused attention, attention distraction, divided attention and selective attention of auditory aspect of normal and hyperactive students and the scores of the focused attention, attention distraction, divided attention and selective attention of the auditory aspect of normal students are higher than the hyperactive students $(\mathrm{P}<0.05)$. Furthermore, the same correlation exists in the visual aspect of the normal and hyperactive students and the scores of the focused attention, attention distraction, divided attention and selective attention of the visual aspect of normal students are higher than the hyperactive students $(\mathrm{P}<0.05)$.
\end{abstract}

Keywords: attention deficit hyperactivity disorder, continuous function of auditory, visual stimuli

\section{Introduction}

Attention Deficit Hyperactivity Disorder (ADHD) is one of the most important psychiatric disorders of children and teenagers. Diagnostic and statistical guide of mental disorders (DSM-V) declares that the main feature of attention deficit-hyperactivity disorder-the stable pattern of attention deficit and hyperactivity- is impulsivity which compared with other people at the same age is more frequent and intense. Attention Deficit-Hyperactivity Disorder (ADHD) shows the stable pattern of attention deficit and hyperactivity (Stoner, 2003) and impulsive behaviors (Owens \& Kozier, 2007) which are more intense than normal children are at the same age. There are three main categories for this disorder: inattention, impulsion, mixed (inattention and impulsion). These symptoms should be chronic and must have been seen at least twice before the age of 12 . Among the troubles which can be made for the parents and the society by these people are the following: these people usually interrupt others and interfere with the affairs, they talk a lot. The scientists believe that the main problem of these people is the sustained attention (Bussing, Mason, Bell, Porter, \& Garvan, 2010). Besides, other problems that can be made by these people are improper relation with the parents, distraction and unfocused attention which leads to dull learning and the other trouble is their impulsiveness which results in making mistakes due to inattention to the details while writing. There is also an inverse relation between hyperactivity and the harmony of the movements. The children who show hyperactivity symptoms would need clinical assistance in teenage period and they cannot control themselves when they are adults. Most of them show aggression, behavioral disorder and compulsory obsession when they grow up (Owens \& Kozier, 2007).

Currently, the researches show the continuity of Attention Deficit Hyperactivity Disorder (ADHD) changes differently from 45\%-55\% (Gaya \& Chung, 2010; Molina et al., 2009; Stain Husen et al., 2003) to 70\% (Begul et al., 2001; Barkley et al., 1990; Hart et al., 1995; Luv et al., 2014; Sibley et al., 2012) and even $80 \%$ (Beaderman et al., 1996; Richards et al., 2014; Riddle et al., 2013) while passing from childhood to adolescence 
period. Beside chronic nature of this disease, a high rate of comorbidity is the other worrying issue that is a feature of ADHD (Miranda, Colomer, Fernández, Presentación, \& Roselló, 2015).

Attention deficit-hyperactivity disorder is a prevalent neurological disorder which accompanies several symptoms in childhood and adulthood (American Psychiatric Association, 2013). Although the behavioral and cognitive aspects of ADHD are known, the special pathophysiological mechanisms and the remaining changes of ADHD brain structure is still vague (Krain \& Castellanos, 2006). Regarding the points mentioned above, it can be stated that different approaches have been employed to treat this disorder. The frequency of the employing these treatments is as follows: pharmacotherapy, cognitive-behavioral therapy, parents training and social skills training (Hanser \& Meisslerand Overs, 2000).

As it was said, one of the helpful treatments which can be very useful for the ADHD sufferers is cognitive function. Cognitive function is the product of processing stages of the brain and is divided into two categories: the first one is rule base function that regulates and controls the thought and the function of a person and is known as the executive function; the second one is the non-rule base function which is based on the excitements, inclinations, social cognition and other effective situational factors. On the other hand, executive function includes cognitive flexibility and the management ability of intervening components of goal-oriented behaviors and the prediction of the results of a performance; furthermore, executive function also consists complex planning of behavior and problem solving. It is supposed that executive function is involved in a wide variety of the daily activities of a person. The activities which necessitate the executive function are time tables and meetings, understanding the medical information, riding a motorcycle, taking proper medicines, cooking, wearing clothes and doing house chores. The executive functions include the self-control behaviors which are employed to protect the performances and to guide the behavior in the framework of purposes and rules (Mahone, Cirino, Cutting, Cerrone, \& Hagelthorn, 2002). To differentiate the executive functions from how and why of human behaviors, a group of scientists classify these functions in different cognitive domains which consists behavior planning and organizing, responserestraining and controlling, function continuity, domination reduction and the ability to start a function. The evidences based on the division of executive function into three components, present a cognition which include control, transmission and update which although are separable, they act all together in the regulation and control process of most of the functions. Among other components which have been introduced by the researchers are planning, decision making and problem solving. There also another classification which categorizes the executive function to main domains including five components of immediate control of response, planning, cognitive flexibility, attention transmission and the working memory (Miyake \& Friedman, 2000).

It should be noticed that according to above observations, there is a difference between the continuous function test of auditory and visual stimuli (IVA) and investigating the efficiency of the children who suffer from attention deficit-hyperactivity disorder. Therefore, regarding the high rate of outbreak of this disorder among the children, the present study can effectively improve the theoretic and applicable results in various fields. Therefore, the researcher is going to investigate if there is a difference between the continuous function test of auditory and visual stimuli (IVA) of the children suffering from the attention deficit-hyperactivity disorder and the normal children of Tehran?

\section{Methodology}

The present descriptive study is of comparative type of research. The participants of this study have been chosen among the hyperactive and normal high school students aging from 12 to 18 in Teheran. Using cluster sampling method, the researcher sampled 30 ADHD sufferers among high school students of Teheran. The suspicious students were labeled as hyperactive students through executing Connors Test in order for the exact and non-overlapping recognition. The normal high school students were chosen using two-step cluster sampling. In the first step, 5 girls' school and 5 boys' school were randomly chosen among Teheran high schools. Then, three classes were again randomly chosen to finally choose the normal sample and were classified as two groups of 30 . Participants' informed consent and proper age are the criteria of being considered as a participant. The participants could quit participating in the research by withdrawal from continuing the study for various reasons, not filling out the questionnaire or just giving back the questionnaire and not intending to take part in IVA test. The descriptive and inferential statistics were employed to analyze and interpret the collected data of the research. While descriptively studying the data, frequency, mean, percentage, density percentage and standard deviation were used and while inferentially analyzing the data, Box and Levene test were respectively done in order to examine the theory of homogeneity of co-variances and variances. Next, the parametric test of multivariable variance test was applied to check if there is a difference between the children suffering from attention deficit-hyperactive disorder and normal children. The statistical findings were analyzed using SPSS-20. 


\subsection{Data Collection}

The data collection tools of the present paper are the demographic questionnaires, the questionnaire of children suffering from attention deficit hyperactive disorder and IVA+AE questionnaire.

\subsubsection{Demographic Questionnaire}

The letter sent: the purpose of collecting data through questionnaire and the necessity of participants' cooperation was intimately explained in this letter and at the end; the researcher thanked and admired the participants' cooperation.

General questions: this section allocate to the general questions to which the participants are supposed to reply. It includes age, education, the number of children, and the salary of the family.

Technical questions: this section employed Connors questionnaire in order to recognize the hyperactivity disorder among the participants and IVA+AE test was also used to investigate the continuous function of auditory and visual stimuli.

\subsubsection{The Questionnaire of Children Suffering from Attention Deficit-Hyperactivity Disorder}

The children who suffer from the attention deficit-hyperactivity disorder and are incapable of learning will be recognized according to DSM-V criteria and also clinical interviewing and following tools.

\subsection{Connors Questionnaire}

This questionnaire has been used in order to recognize the hyperactive children. The reliability of this questionnaire, that is 0.71 , was calculated through dividing it into two groups of odds and evens. Besides, the validity of it has also been authenticated by neurologists (Ghamari Givi, 1997).

The questionnaire includes 48 clauses of which 6 investigate hyperactivity factors including attention disorder-focus (learning), conduct disorder, impulsivity disorder, hyperactivity, psychosomatic disorder, and anxiety problem (Connors et al., 1998). In a study done by Khushabi et al., the reliability of the questionnaire (0.93) was calculated using Cronbach Alfa. They also found out that the highest score which can be achieved by a normal child is 38 (Khushabi et al., 2002). Kronenberger and Meyer state that Connors has mentioned to the scores more than 60 as higher than average (Kronenberger et al., 2001).

\section{IVA+AE Questionnaire}

IVA + AE test was edited based on the recognition instruction and statistics of mental disorders of DSM-V and it concerns the recognition and division of different DHDs including attention deficit, hyperactive, combined type and unidentified type (NOS). The developers of this test never tried to artificially make a "special cut-off point". On the other hand, those who suffer from acute or severe brain damage are recognized as "severely damaged" in this test. IVA test, according to Kjellberg model (1987), evaluated attention as a multidimensional cognitive element. Attention is categorized into five dimensions in this model.

(1) Focused Attention: capability of correctly reacting to auditory and visual stimuli presented in this test (no one). This dimension of attention is evaluated by subscales of prudence and vigilance.

(2) Sustained Attention: capability of sustainably and validly continuing reaction pattern. This dimension of attention is made through changes which are occurred while reacting time during doing the test. The related scales to this dimension are stamina, consistency and focus.

(3) Selective Attention: recognition capability to correctly respond to the target stimulus and inhibiting the wrong response while facing false stimuli. The related scales are prudence, comprehension, and vigilance.

(4) Alternating Attention: cognition flexibility in attention transfer from visual to auditory and vice versa is called alternating attention. The difference between the auditory and visual scales of speed, balance, readiness, consistency and focus can show the strength or weakness of this very dimension of attention.

(5) Divided Attention: the capability of simultaneous reaction to different tasks is called divided attention. A balance is made between the speed and accuracy of the participants in two auditory and visual dimensions. The difference between the scores of speed scale and prudence would examine the problems of divided attention.

The standard score of IVA test and descriptive dimensions of it are stated in the following table. 


\section{Findings}

The table of descriptive findings is shown first and then the related findings to the research hypotheses are presented.

Table 1. Descriptive statistics related to the variable of auditory dimension of different types of attention

\begin{tabular}{|c|c|c|c|c|c|}
\hline Dimension & Variable & Group & Mean & Median & Standard Deviation \\
\hline \multirow{10}{*}{ Auditory } & Focused & ADHD & 77.10 & 76.0 & 17.13 \\
\hline & Attention & Normal & 104.07 & 105.50 & 7.96 \\
\hline & Alternating & ADHD & 90.72 & 93.20 & 11.42 \\
\hline & Attention & Normal & 96.41 & 96.40 & 8.03 \\
\hline & Sustained & ADHD & 83.37 & 89.0 & 17.20 \\
\hline & Attention & Normal & 87.61 & 86.33 & 10.79 \\
\hline & Divided & ADHD & 94.47 & 95.0 & 9.38 \\
\hline & Attention & Normal & 102.95 & 101.50 & 8.52 \\
\hline & Selected & ADHD & 73.53 & 78.17 & 15.52 \\
\hline & Attention & Normal & 97.85 & 101.67 & 11.32 \\
\hline \multirow{10}{*}{ Visual } & Focused & ADHD & 80.74 & 80.0 & 14.24 \\
\hline & Attention & Normal & 97.93 & 99.50 & 7.78 \\
\hline & Alternating & ADHD & 97.87 & 97.80 & 6.97 \\
\hline & Attention & Normal & 99.20 & 100.80 & 8.72 \\
\hline & Sustained & ADHD & 93.31 & 94.0 & 10.42 \\
\hline & attention & Normal & 96.57 & 98.67 & 12.53 \\
\hline & Divided attention & ADHD & 83.96 & 84.50 & 8.90 \\
\hline & & Normal & 95.59 & 97.0 & 5.92 \\
\hline & Selected & ADHD & 76.97 & 78.0 & 15.45 \\
\hline & Attention & Normal & 90.73 & 92.33 & 11.29 \\
\hline
\end{tabular}

Taking Table 1 into notice, we will figure out that the score of selected attention for the students suffering from attention deficit hyperactivity disorder is 73.53 which compared with the standard score of IVA that ranges from 70 to 80 , it can be concluded that the people suffering from attention deficit hyperactivity disorder are categorized in weak group. While the score of the selected attention of normal students equals 97.85 which compared with the standard score of IVA test are classified as higher than average students. Besides, the score of selected attention of the students suffering from attention deficit hyperactivity disorder is 76.97 which compared with the standard score of IVA test that ranges from 70 to 80 . So, the people recognized as ADHD sufferer are classified as weak category. While the score of selected attention of normal students is 90.73 and this score categorizes the students in the medium class.

While examining the normality of the data, the null hypothesis based on the fact that the data are normally distributed, is tested in the tolerance of $5 \%$. Therefore, if the significant correlation is more than 0.05 , there won't be any reason to reject the null hypothesis. On the other hand, the data are normally distributed. The significant correlation achieved for the research variables in both ADHD sufferer students and normal students will be more than 0.05 , so the research variables are normal. The significant correlation of the variables is more than 0.05 , therefore the variance of both groups of students are equal.

Table 2. The Results related to the analysis of multivariable variance of auditory dimension variable of different types of attention

\begin{tabular}{cccccc}
\hline Test Name & Value & Hypothesis df & Error df & F Test & Significant correlation \\
\hline Pillay trace test & 0.727 & 5 & 45 & 23.93 & $<0.001$ \\
\hline
\end{tabular}


As it has been illustrated in Table 2, the significant correlation of the auditoryvariable of different types of attentiongroup, i.e., normal students and the students suffering from attention deficit hyperactivity disorder, is less than 0.05 except sustained attention; it means that there is a significant correlation between the normal students and those who suffer from attention deficit hyperactivity disorder from one of the dimensions of dependent variables (focused attention, alternating attention, divided attention, selected attention among the variables of visual variables).

Table 3. The results related to the analysis of multivariable variance of auditory dimension variable of different types of attention

\begin{tabular}{cccccccc}
\hline Variable & $\begin{array}{c}\text { Sum of } \\
\text { Squares }\end{array}$ & $\mathrm{df}$ & $\begin{array}{c}\text { Mean of } \\
\text { Squares }\end{array}$ & $\mathrm{F}$ & Sig & Eta $^{2}$ & $\begin{array}{c}\text { Observed } \\
\text { power }\end{array}$ \\
\hline $\begin{array}{c}\text { Focused } \\
\text { Attention }\end{array}$ & 9928.025 & 1 & 9928.025 & 55.77 & 0.000 & 0.532 & 1.00 \\
$\begin{array}{c}\text { Alternating } \\
\text { Attention }\end{array}$ & 474.293 & 1 & 474.293 & 4.68 & 0.035 & 0.087 & 0.564 \\
Sustained & 41.908 & 1 & 41.908 & 0.202 & 0.655 & 0.004 & 0.072 \\
Divided & 1367.317 & 1 & 1367.317 & 18.612 & 0.000 & 0.275 & 0.988 \\
Attention & & & & & & & \\
Selected & 8042.996 & 1 & 8042.996 & 29.475 & 0.000 & 0.376 & 1.00 \\
Attention & & & & & & & \\
\hline
\end{tabular}

As it has been demonstrated in Table 3, the variable of focused attention among the auditory dimension present the value of 55.77 in $\mathrm{F}$ test which has a significant correlation with the significant correlation of 0.000 because it is less than 0.05. These findings show that there is a significant correlation between normal students and the students who are suffering from attention deficit hyperactivity disorder in focused attention among the auditory dimension. Regarding the achieved mean of the scores of focused attention of normal students is significantly more than students suffering from ADHD; however, the students categorized as ADHD sufferer are classified in weak class and normal students are classified in higher than average class. Furthermore, the $\mathrm{F}$ test for the alternating attention of auditory dimension shows the value of 4.68 which has a significant correlation with 0.035 because it is less than 0.05 . The same test provides the value of 0.202 that doesn't have a significant correlation because it is more than $0.05(0.655)$. Divided variable which is a subdivision of auditory dimension gets the 18.612 value which has a significant correlation with the value of 0.000 since it is less than 0.05 . The last variable, selected attention was scored 29.475 in F test, which is significantly correlated $(0.000)$ because it is less than 0.05 .

Table 4. The results related to the analysis of multivariable variance of visual dimension variable of different types of attention

\begin{tabular}{cccccc}
\hline Test Name & Value & Hypothesis df & Error df & F & Sig \\
\hline Pillay Trace Test & 0.456 & 5 & 47 & 7.882 & $<0.001$ \\
\hline
\end{tabular}

As it has been shown in Tables 1-4, taking the visual dimension variable of different types of attention-the normal students and the ADHD sufferer into notice, it can be seen that the significant correlation of the tests would be less than 0.05 which means that regarding at least one of the dependent variables (focused attention, divided attention, selected attention among the visual dimension), there is a significant correlation between the normal students and those suffering from ADHD. 
Table 5. The results related to the analysis of multivariable variance of visual dimension variable of different types of attention

\begin{tabular}{|c|c|c|c|c|c|c|c|}
\hline Variable & $\begin{array}{l}\text { Sum of } \\
\text { Squares }\end{array}$ & $\mathrm{df}$ & $\begin{array}{l}\text { Mean of } \\
\text { Squares }\end{array}$ & $\mathrm{F}$ & Sig & $\mathrm{Eta}^{2}$ & $\begin{array}{c}\text { Observed } \\
\text { power }\end{array}$ \\
\hline Focused attention & 3975.442 & 1 & 3975.442 & 30.87 & $<0.001$ & 0.377 & 1.0 \\
\hline $\begin{array}{l}\text { Alternating } \\
\text { attention }\end{array}$ & 23.293 & 1 & 23.293 & 0.369 & 0.546 & 0.077 & 0.092 \\
\hline $\begin{array}{l}\text { Sustained } \\
\text { attention }\end{array}$ & 236.215 & 1 & 236.215 & 1.926 & 0.171 & 0.036 & 0.275 \\
\hline Divided attention & 1786.193 & 1 & 1783.193 & 31.964 & $<0.001$ & 0.385 & 1.0 \\
\hline Selected attention & 2412.343 & 1 & 2412.343 & 13.294 & $<0.001$ & 0.207 & 0.947 \\
\hline
\end{tabular}

As it is shown in Table 5, the $\mathrm{F}$ test for alternating attention of visual dimensions is 0.369 and the significant correlation is 0.546 which is not significant because it is more than 0.05 . The findings state that there is no significant correlation between normal and ADHD sufferer students in relation to alternating attention of visual dimensions. Regarding the means of the scores of the normal students in relation to alternating attention of visual dimensions is more than that of those students who suffer from attention deficit hyperactivity disorder, this difference is not significant and the ADHD students and normal students are categorized as higher than average group. Moreover, the F test of sustained attention of visual dimensions is 1.926 and the significant correlation of it is 0.171 which is more than 0.05 , so it is not significantly correlated. The value of $\mathrm{F}$ test for divided attention is 31.964. The significant correlation is 0.000 and it is correlated because it is less than 0.05 . The selected attention of visual dimension has a $\mathrm{F}$ test of 13.294, of which the significant correlation is 0.000 and therefore significantly correlated because it is less than 0.05 .

\section{Discussion and Conclusion}

As it was presented in the findings of the research and according to what is shown in Table 1, auditory dimension variable of different types of attention the significant correlation of both groups of normal students and those students who suffer from ADHD is less than 0.05 except sustained attention, which means that there is a significant correlation between normal students and those who suffer from ADHD at least in relation to one of dependent variables (focused attention, alternating attention, divided attention, selected attention of auditory dimensions).

These findings state that there is a significant correlation between normal students and ADHD sufferer students in relation to focused attention of auditory dimensions. Regarding the achieved means, the score of normal students in focused attention of auditory dimensions is significantly more than the scores of ADHD sufferers. The ADHD sufferers are categorized as weak group while the normal students have been classified as higher than average group. Furthermore, the findings show that there is a significant correlation between the normal and ADHD sufferer students in relation to alternating attention of auditory dimension. Taking the achieved scores into notice, Table 3 shows that the score of alternating attention of auditory dimension is significantly more than score of ADHD students. Besides, the normal students and ADHD students do not show a significant difference in relation to sustained attention of auditory dimension but the divided attention of auditory dimension of both groups is significantly correlated between normal and ADHD students. The same results exist for the selected attention of auditory dimension of both groups of students. Looking at the means of scores of normal students and ADHD students, we can see that the score of normal students is significantly more than ADHD students. The ADHD students are grouped as weak and the normal students are classified as higher than average group.

The present research and the following researches have the same results:

Jackson (2003) studied the methods of music therapy and their role in early treatment of primary students who suffered from ADHD. Another research was done by Garcia et al. in 2007; they tested the auditory attention of 40 children aged from 6 to 9. Janatian (2006) studied the effectiveness of playing on the reduction of the symptoms of hyperactivity disorder among the students of third and fourth grade of primary schools of Esfahan.

Zemestani and SeifNaraghi (2009) did a study on the particulars of auditory memory of the children who suffer from ADHD. Karimi and Zare (2013) investigated the effect of music on the sustained attention of the children who suffer from attention deficit hyperactivity disorder. Sarly et al. (2013) did a study titled "the effect of 
computerized auditory tasks on the sustained attention of 20 children (aged from 9 to 11) who suffer from attention deficit hyperactivity disorder.

To explain these findings, it can be stated that there is a difference between auditory dimension of different kinds of attention in normal people and those who suffer from attention deficit hyperactivity disorder; the hearing ability is defined as a skill in learning process. As it was supposed, one of the features of this disorder is behavioral unsustainability, the children who have problem in auditory perception don't have a problem in hearing, they have problem in auditory perception. One of the features of the people who suffer from ADHD in auditory dimension is their inattention to their surrounding environment and this inattentiveness will result in decentralizing, failing to complete their assignments, making mistakes while doing tiring assignments and frequent changing of the activity. Furthermore, the continuity of reduction of attention deficit hyperactivity disorder in the auditory dimension of the children is caused by the fact that the children need more time to generalize their learning to the outside environment. To confirm the results of the studies done on ADHD, there are some evidences that show ADHD sufferer, compared with normal people, act slower in doing their auditory assignments and processing the auditory stimuli. According to the theory of information process, it can be said that the problem of these people is getting the input and recognizing the received information from the environment and this fact leads to auditory or visual incompetence and consequently, the person with good hearing ability will have problem in getting the received sounds. According to this view, the function of human mind can be analyzed step by step; it includes inputs, storage and outputs. Meanwhile, the attention is paid to the first step of storing the information in the brain (inputs) which leads to the selective process of the inputs among the wide range of stimuli. The existence of deficiencies in processing skills would result in the indication of problems in the processing cycle and this will cause the input not be fully processed and some of the delivered information is removed.

Also it is shown that, visual dimension variable of different types of attention the significant correlation of all the tests of all the normal and ADHD sufferer students is less than 0.05 except alternating attention, sustained attention which means that there is a significant correlation between the normal students and those who suffer from attention deficit hyperactivity disorder at least in relation to one of dependent variables (focused attention, divided attention, selected attention of variables of visual dimension).

The findings indicate that there is a significant correlation between normal students and the ADHD students in relation to focused attention. Regarding the achieved means of focused attention of normal students are meaningfully more than ADHD students. There isn't a significant correlation between normal and ADHD students in relation to alternating attention of variables of visual dimension. Taking the achieved means of alternating attention of normal students into notice, it is shown that the scores of normal students are more than ADHD students and this difference is not significantly correlated and the members of normal group and ADHD group are both classified as higher than average class. Besides, the findings illustrate that there isn't a significant correlation between normal and ADHD students in relation to sustained attention of visual dimension but there is a significant correlation between the normal and ADHD students in relation to divided attention of visual dimension. Regarding the calculated means of normal students in divided attention of visual dimension, it is observed that the means are significantly more than the score of the students suffering from attention deficit hyperactivity disorder. The difference between normal and ADHD students in relation to selective attention of visual dimension is also significantly correlated. The means of normal students of selective attention is more than the scores of ADHD students. The ADHD students were categorized as weak and the normal students were grouped as higher than average.

The results of this study consist with Moorey (2000), Taghavi (2011), Karimi and Zare (2013) and Ibrahim pour (2013). Ibrahim pour (2013) investigated the impact of computerized cognitive empowerment on the function of active memory, attention, language ability, spatial visual ability and the fluency of old people.

Explaining the findings, it can be added that visual perception is one of sensory ways through which the human being can gain lots of information and save them in his memory. Visual perception is an essential factor in learning process and those people who suffer from some sort of learning disabilities, like the ADHD sufferers, are not able to make good relationship compared with their peers, they disobey the rules, swear, lie, speak impolitely, can't restraint, take lots of risks; they are aggressive and are not able to solve social problems because they are not smart enough or suffer from special learning disabilities, they cannot concentrate, they get distracted easily, they cannot fully control the impulses and make more destruction in comparison with normal children; besides, the hyperactive children are defined as sad and restless children who are not able to stay in one place for long. 
The children who suffer from attention deficit hyperactive disorder cannot solve complicated tasks because they are not able to organize and focus their sustained attention on doing something; it can be further said that since the children who suffer from attention deficit hyperactivity disorder are weak at practical intelligence compared with verbal intelligence and since they have deficiency in perceptive-dynamic skills and spatial organization, they perform poorly in graphical tests compared with their peers. The existence of deficiency in sustained attention and this deficiency would cause the children to be easily distracted even after choosing the best stimuli and then they cannot concentrate on doing the rest of task. The results of this paper approve this issue. The results of this paper are only applicable to a specific sex, education and age group. Therefore, the generalization of the results to other sex or age group is limited. Other limitation of this study was the shortage of national and international sources to make a more comprehensive literature review. So it is suggested to other scientists to work more extensively on different age group and other educational institutes in future researches. Moreover, since the students who suffer from attention deficit hyperactivity disorder have pay less visual and auditory attention compared with normal people. Then, it is a good suggestion to the primary school counselors, clinics and family consultation center to try harder to recognize and then treat the attention deficit hyperactivity disorder. Totally speaking, the findings of the present paper show that empowerment through IVA would affect the efficiency of the ADHD children, so the cognitive empowerment is of high importance in preventing from the occurrence of such cognitive disorders.

\section{References}

American Psychiatric Association. (2013). The diagnostic and statistical manual of mental disorders (5th ed.). Psychiatric Pub. Incorporated.

Bagwell, C. L., Molina, B., Pelham, W. E., \& Hoza, B. (2001). Attention-deficit hyperactivity disorder and problems in peer relations: Predictions from childhood to adolescence. Journal of American Academy of Child and Adolescent Psychiatry, 40, 1285-1292. http://dx.doi.org/10.1097/00004583-200111000-00008

Barkley, R. A., Fischer, M., Edelbrock, C. S., \& Smallish, L. (1990). The adolescent outcome of hyperactive children diagnosed by research criteria: An 8 year prospective follow-up study. Journal of American Academy of Child and Adolescent Psychiatry, 29, 546-557. http://dx.doi.org/10.1097/00004583-199007000-00007

Barrio-Arranz, G., Aja-Fernández, S., \& Alberola-López, C. (2015). Attention deficit/hyperactivity disorder and medication with stimulants in young children: A DTI study. Progress in Neuro-Psychopharmacology \& Biological Psychiatry, 57, 176-184. http://dx.doi.org/10.1016/j.pnpbp.2014.10.014

Biederman, J., Faraone, S. V., Milberger, S., Curtis, S., Chen, L., \& Marrs, A. (1996). Predictors of persistence and remission of ADHD: Results from a four-year prospective follow-up study of ADHD children. Journal of American Academy of Child and Adolescent Psychiatry, 35, 343-351. http://dx.doi.org/10.1097/00004583-199603000-00016

Bussing, R., Mason, D. M., Bell, L., Porter, P. H., \& Garvan, C. (2010). Adolescent Outcomes of childhood attention Deficit/Hyperactivity Disorder in a Drivers community sample. Journal of American Academy of Child and Adolescent Psychiatry, 49(6), 565-605. http://dx.doi.org/10.1016/j.jaac.2010.03.006

Gau, S. S. F., \& Chang, P. S. (2013). Maternal parenting styles and mother-child relationship among adolescents with and without persistent attention-deficit/hyperactivity disorder. Res DevDisabil, 34, 1581-1594. http://dx.doi.org/10.1371/journal.pone.0128325

Hanser, S., Meissler, K., \& Ovevs, R. (2002). Kids together: A group play therapy model for children with ADHD symptomalogy. Journal of Child and Adolescent Group therapy, 10(4).

Hart, E., Lahey, B., Loeber, R., Applegate, B., \& Frick, P. J. (1995). Developmental change in attention-deficit hyperactivity disorder in boys: A four-year longitudinal study. Journal of Abnorm Child Psychol, 23, 729-749. http://dx.doi.org/10.1007/BF01447474

Krain, A. L., \& Castellanos, F. X. (2006). Brain development and ADHD. ClinPsychol Rev, 26, 433-444. http://dx.doi.org/10.1016/j.cpr.2006.01.005

Law, E. C., Sideridis, G. D., Prock, L. A., \& Sheridan, M. A. (2014). Attention deficit/hyperactivity disorder in young children. Pediatrics, 133, 659-667. http://dx.doi.org/10.1542/peds.2013-3433

Mahone, E. M., Cirino, P. T., Cutting, L. E., Cerrone, P. M., Hagelthorn, K. M., Hiemenz, J. R., ... Denckla, M. B. (2002). Validity of the behavior rating inventory of Executive function in children with ADHD and/or 
Tourette syndrome. Archives of Clinical Neuropsychology, 17, 643-662. http://dx.doi.org/10.1016/S0887-6177(01)00168-8

Miranda, A., Colomer, C., Fernández, M. I., Presentación, M. J., \& Roselló, B. (2015). Analysis of Personal and Family Factors in the Persistence of Attention Deficit Hyperactivity Disorder: Results of a Prospective Follow-Up Study in Childhood. PLoS ONE, 10(5). http://dx.doi.org/10.1371/journal.pone.0128325

Miyake, A., \& Friedman, N. P. (2000). The unitary and diversity of executive function and their contribution to complex frontal lobe tasks, a latent variable analysis. Cognitive Psychology, 41, 49-100. http://dx.doi.org/10.1006/cogp.1999.0734

Molina, B. S., Hinshaw, S. P., Swanson, J. M., Arnold, L. E., Vitiello, B., \& Jensen, P. S. (2009). MTA at 8 years: Prospective follow-up of children treated for combined-type ADHD in a multisite study. Journal of American Academy of Child and Adolescent Psychiatry, 5, 484-500. http://dx.doi.org/10.1097/CHI.0b013e31819c23d0

Owens, J. S., Goldfine, M. E., Evangelista, N. M., Hoza, B., \& Kaiser, N. M. (2007). A critical review of self-perceptions and the positive illusory bias in children with ADHD. Clinical child and family psychology Review, 10, 335-351. http://dx.doi.org/10.1007/s10567-007-0027-3

Richards, J. S., Arias Vásquez, A., Rommelse, N. N. J., Oosterlaan, J., Hoekstra, P. J., \& Franke, B. (2014). A follow-up study of maternal expressed emotion toward children with attention-deficit/hyperactivity disorder (ADHD) relation with severity and persistence of ADHD comorbidity. Journal of American Academy of Child and Adolescent Psychiatry, 53, 311-319. http://dx.doi.org/10.1016/j.jaac.2013.11.011

Riddle, M. A., Yershova, K., Lazzaretto, D., Paykina, N., Yenokyan, G., \& Greenhill, L. (2013). The preschool attentions-deficit/hyperactivity disorder treatment study (ATS) 6 year follow. Journal of American Academy of Child and Adolescent Psychiatry, 52, 264-278. http://dx.doi.org/10.1016/j.jaac.2012.12.007

Sibley, M. H., Pelham, W. E. J., Molina, B. S. G., Gnagy, E. M., Waschbusch, D. A., \& Garefino, A. C. (2012). Diagnosing ADHD in adolescence. Journal of Consult ClinPsychol, 80, 139-150. http://dx.doi.org/10.1037/a0026577

Steinhausen, H. C., Drechsler, R., Földényi, M., Imhof, K., \& Brandeis, D. (2003). Clinical course of attention deficit hyperactivity disorder from childhood towards early adolescence. Journal of American Academy of Child and Adolescent Psychiatry, 42, 1085-1092. http://dx.doi.org/10.1097/01.CHI.0000070241.24125.A3

Stone, G. D., \& DePaul, G. J. (2003). ADHD in schools: Assessment and intervention strategies (2nd ed.). New York: Guilford Publications Inc.

\section{Copyrights}

Copyright for this articleis retained by the author(s), with first publication rights granted to the journal.

This is an open-access article distributed under the terms and conditions of the Creative Commons Attribution license (http://creativecommons.org/licenses/by/4.0/). 